\title{
RESEÑA
}

\section{Japón y sus alternativas de desarrollo económico hacia el futuro}

DOI: $10.32870 /$ mycp.v8i23.617

Alejandra María Martínez Leyte ${ }^{1}$

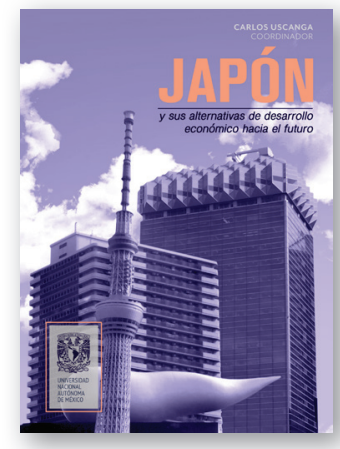

Japón y sus alternativas de desarrollo económico hacia el futuro, Carlos Uscanga (coordinador), México, UNAM, Colección Universitaria de Estudios Asiáticos, vol. 6, 2017.

Durante los últimos 25 años el gobierno de Japón no ha sido capaz de resolver el aletargamiento económico luego del quiebre de la burbuja financiera propiciada por las políticas monetarias del Banco Central de Japón y las imposiciones monetarias de los Acuerdos Plaza y Louvre; es por ello que el gobierno de Shinzo Abe implementó, desde 2012, una serie de estrategias para reactivar la economía de su país. Este proyecto es conocido como Abenomics, dentro del cual el Acuerdo de Asociación Transpacífico (TPP, por sus siglas en inglés) es uno de los principales medios para acelerar la competitividad de las empresas japonesas a nivel regional y mundial. Carlos Uscanga coordina este trabajo en conjunto con otros nueve autores, quienes abordan la situación comercial y monetaria de Japón en la actualidad, las Abenomics, el TPP y sus consecuencias políticas y sociales.

Este esfuerzo académico se propone tres objetivos abordados transversalmente en cada uno de los ocho capítulos que lo integran. El primer propósito es plantear al lector el escenario económico japonés contemporáneo; el segundo es la exposición de las Abenomics y sus impactos sociales; el tercero es analizar la participación de Tokio en la consolidación del TPP.

Víctor López Villafañe da pie a la discusión planteando un breve pero preciso recorrido de historia económica de Japón desde 1950, etapa cuando inició su alto crecimiento sostenido, hasta la década de los noventa cuando

1. Universidad Nacional Autónoma de México (UNAM), Facultad de Ciencias Políticas y Sociales. Ciudad Universitaria, Col. Copilco, Alcaldía Coyoacán, C.P. 04510, Ciudad de México, México. ORCID: http://orcid.org/0000-0002-7667-8606. Correo electrónico: ale.mtz.leyte@gmail.com 
sus índices de desempeño económico se vieron estancados. En esta sección se enlistan los factores de orden interno y externo, así como condiciones sociales y políticas que hicieron posible el "milagro económico japonés", mismo que devolvió a la población una relativa equidad en la distribución del ingreso. Por último, el autor señala las lecciones que los países en desarrollo pueden aprender de la experiencia japonesa industrial, donde sobresalen sus estrategias de absorción tecnológica.

Posteriormente, Ulises Granados expone el Acuerdo de Asociación Económica Regional Total (RCEP, por sus siglas en inglés), en el que Japón adscribe un constante interés, al igual que en el TPP y el Tratado Trilateral de Libre Comercio con China y Corea del Sur (CJKFTA, por sus siglas en inglés); este último se encuentra hoy día en estado de impasse. Estos acuerdos comerciales de orden regional son un medio fundamental para cubrir una de las principales estrategias del proyecto Abenomics: la promoción de más comercio e inversión mediante la activa participación de acuerdos de asociación económica en la región. Este capítulo divide su estudio en: 1) identificar qué es RCEP; 2) las etapas de negociaciones; 3) su relevancia para la administración de Abe, y 4) los retos que ha enfrentado el Acuerdo durante las negociaciones. Finalmente, Granados considera que si Tokio no logra concretar estos acuerdos, se arriesga a perder el liderazgo de la integración regional y daría paso a China a ocupar este puesto.

Complementariamente, Asenet Martínez aborda el recorrido histórico del TPP surgido en la región de Asia Pacífico. El Acuerdo de Asociación Transpacífico abre la posibilidad de lograr avances respecto a la integración económica de esta región, de inmensa actividad económica, a través de medidas jurídicamente vinculantes y planteando objetivos claros en materia de intercambio comercial. Para abordar el tema, la autora divide su estudio en antecedentes del TPP; un recorrido de su desarrollo, y los puntos más sobresalientes de su versión final.

Yasuhiro Tokoro presenta la trayectoria histórica de la actual política comercial de Japón con el objetivo de tener un mejor entendimiento sobre su participación e intenciones en el TPP. A lo largo de las secciones de este capítulo se exploran las oportunidades y retos que el Acuerdo representa para Japón en sus diferentes sentidos, siendo la agricultura y la ganadería los sectores más sensibles para Tokio debido a su estricta política arancelaria en productos de estas áreas; mientras que el sector de servicios y las compañías multinacionales japonesas prometen verse beneficiados por el TPP. Para concluir, Tokoro expone las más importantes críticas al Acuerdo: el riesgo para 
la soberanía alimentaria japonesa y la posición vulnerable en la que se coloca a las pequeñas y medianas empresas niponas.

Para continuar profundizando el análisis en cuanto al TPP, Vladimir Acosta se da a la tarea de evaluar si las negociaciones de Tokio en la consolidación del TPP resultaron un triunfo para la administración de Abe. En este capítulo se presentan los puntos en los cuales Japón tuvo que ceder para dar paso a ganancias en el plan Abenomics. Sin embargo, también existe el riesgo de una estanflación debido al relajamiento de la política monetaria y al aumento de la deuda; asimismo, hay sectores al interior que han presentado una gran oposición al Acuerdo, destacando entre éstos las cooperativas agrícolas, grupo que representa un peso considerable en la política japonesa. Para finalizar la discusión, el autor expone la importancia geopolítica del TPP para Japón como un método de contención en la expansión de China.

Por otra parte, Melba Falck expone en qué consisten puntualmente las Abenomics. En este capítulo la autora desarrolla los antecedentes de estas reformas, tomando como referencia las décadas de estancamiento económico japonés desde los noventa. Finalmente se describen los tres principales ejes de este proyecto: 1) política monetaria; 2) política fiscal; 3) reforma estructural, misma que se divide en: agrícola, sector salud, mercado laboral y energía.

María Elena Romero y Martha Loaiza se dan a la tarea de abordar las Abenomics desde una perspectiva social y crítica, exponiendo cómo estas estrategias únicamente han favorecido a grupos poderosos interesados en crear un ambiente conveniente para sus intereses políticos. La población japonesa, mayormente de clase media, actualmente resiente los efectos negativos de esa falta de inclusión en el proyecto. Dentro del apartado se expone cómo el incremento del gasto en obra pública y los incentivos empresariales no se han permeado como beneficios directos para la población, empero hubo recortes a la asistencia social y se incrementó el impuesto al consumo del 5 al 8\%. Asimismo, el capítulo demuestra que existen poblaciones vulnerables en la sociedad japonesa: los niños, los jóvenes, especialmente aquellos que provienen de hogares de madres solteras, y los ancianos. Para cerrar este capítulo, las autoras señalan estrategias y premisas para poner énfasis en el reconocimiento del aumento de la pobreza en la sociedad japonesa y el deber de Tokio por brindarle una oportuna atención.

El último capítulo, escrito por Alicia Girón, muestra el papel del Banco Central de Japón (BoJ, por sus siglas en inglés) como actor fundamental para hacer posible el "milagro económico japonés" a través del control de las tasas 
de interés y la apreciación del yen frente al dólar; sin embargo, estas medidas, más los reajustes del yen impuestos por Washington en los Acuerdos Plaza y Louvre, provocaron el inevitable quiebre de la burbuja financiera que cimbró la economía japonesa. Actualmente el BoJ se encuentra comprometido con la administración de Abe para terminar con el aletargamiento monetario del país; sin embargo, existe una compleja coyuntura internacional en donde la especulación y la expansión del comercio chino representan los principales retos para las estrategias económicas del gobierno de Japón y el BoJ.

Al finalizar la lectura de Japón y sus alternativas de desarrollo económico hacia el futuro, el interesado en este tema contará con un bagaje más profundo sobre las Abenomics, especialmente en el área de comercio exterior y los medios a través de los cuales el gabinete de Abe planea ejecutar estas estrategias económicas al exterior, entre los que sobresale el TPP. Sin embargo, en el libro también se describen otros acuerdos regionales del interés de Japón, tales como el RCEP y el CJKFTA. En el caso del TPP, esta obra ofrece un examen sobre las implicaciones de Japón en el mismo: antecedentes, desarrollo de negociaciones, intereses, ganancias, costos, oposición al interior e impacto social. Todo lo anterior complementado con valiosas tablas y cuadros que sintetizan el contenido del Acuerdo y los costos, principalmente sociales, que representa para el gobierno de Japón este proyecto.

El libro resulta ser un material enriquecedor para situar a los estudiosos de Japón y del este de Asia en un contexto actualizado y completo de la política económica japonesa encabezada por el primer ministro Shinzo Abe. Este tomo ofrece principalmente útiles elementos de apoyos históricos, políticos, sociales y económicos para reforzar el análisis de las Abenomics frente al TPP y fungir como fuente de referencia, imprescindible, para abordar la cuestión del desarrollo económico del Japón contemporáneo y sus posibles perspectivas. my 